Journal of Learning and Development Studies (JLDS)

DOI: 10.32996/jlds

Journal Homepage: www.al-kindipublisher.com/index.php/jlds

\title{
Would-be Language Teachers' Perceptions and Challenges Towards Synchronous Language Learning
}

\author{
Kathlyn P. Aranas \\ College of Teacher Education, Western Mindanao State University, Philippines \\ Corresponding Author: Kathlyn P. Aranas, E-mail: kathlynaranas1025@gmail.com
}

\author{
ARTICLE INFO \\ Received: September 11, 2021 \\ Accepted: October 04, 2021 \\ Volume: 1 \\ Issue: 1 \\ DOI: $10.32996 / j$ lds.2021.1.1.2
}

\section{KEYWORDS}

Online learning, Synchronous

learning, Perceptions, Challenges,

Would-be language teachers.

\section{ABSTRACT}

Believed to be a practical solution to eliminate the possibilities of any learning gap to befall, the adaption of online learning specifically the implementation of the synchronous mode of teaching and learning has been practiced in various universities in the arena of education amidst the covid-19 outbreak. In light of this, the present study sought to investigate the different perspectives of would-be language teachers towards synchronous learning. Moreover, this investigation aimed to determine the challenges encountered by the students during the course of learning. The participants of the study were seven students in the tertiary level taking a bachelor's degree either in English or Filipino. Essentially, a descriptive qualitative research design was employed and individual in-depth interviews were conducted. Furthermore, thematic analysis was utilized to analyze the data gathered. With reference to the findings of this study, it has been noted that the respondents perceive synchronous learning differently, which includes both positive and negative remarks. In addition, internet connectivity issues, limited interaction in virtual platforms, technical difficulties, distractions in the environment, and lack of gadgets were the evident challenges experienced by the students during synchronous learning sessions.

Published by Al-Kindi Center for Research and Development, London, United Kingdom

Copyright (c) the author(s). This open access article is distributed under a Creative Commons Attribution (CC-BY) 4.0 license (https://creativecommons.org/licenses/by-nc-nd/4.0/)

\section{Introduction}

Withstanding the present crisis regarding the scourging effect of COVID-19, various sectors in the society have extensively engaged in employing and developing alternatives in pursuit to create a 'new normal' that will permit individuals to continue their daily functions in the society, the education sector is one of which. In spite of the outbreak, the field of education has found a way to ensure that learners will still be able to enjoy the privilege of learning. Relatively, Khalil et al. (2020) contended that through the adaption of online learning, a safe and secured learning process will commence. This means that it will allow both the students and the instructors to be engaged in a meaningful learning experience amidst the pandemic while having a guarantee that both parties will not be put in the line of the danger that the pandemic imposed.

Essentially, as the advancement of technology takes place from time to time, it has undoubtedly received considerable attention from the public and eventually found its purpose in helping improve the educational system, hence online education came to exist. Wherein, it offers the public a new variety of the teaching and learning process through the employment of technology which plays a significant role in the arena of education. Corroborating this statement is the contention of Young (2011, as cited in Malik et al., 2017) that online education has already been widely acknowledged, to an extent that it is considered an integral part of the teaching process. It is also highly believed to be shaping and transforming the learning environment of the $21^{\text {st }}$ century (Mcloughlin \& Lee, 2010). Generally, when the traditional face-to-face classes were put on hold, Electronic Learning (E-learning) was employed in various schools and universities, bringing together students and teachers through distance learning (Driscoll, 2002). Moreover, E-learning was implemented through the use of two different methods, synchronous and asynchronous learning.

Relatively, the synchronous model enables a student and the teacher to have real-time communication and have an online live interaction with each other (Shahabadi \& Uplane, 2015). While the asynchronous model does not require live communication through real-time and gives the students the privilege to learn at one's own learning pace (Horton, 2000; Rosenberg, 2001). In spite of the popularity of the two, Karal et al. (2011) claimed that the synchronous model is more advantageous rather than the 
latter one. The reason behind this claim is that the synchronous model offers real-time class discussions wherein, the students and the teacher can interact through video conferencing which according to Gough (2006) is the transfer of video and data between two or more different communication lines and provide the learners an atmosphere just like that of the traditional classroom. Furthermore, through this kind of learning modality, the teacher can also provide the students direct feedback which is an important part of the learning process. In addition, this kind of learning can provide learners an environment in which they share their ideas and thoughts and be guided by the instructor during class discussions, all done through the utilization of a virtual learning platform. Hence, students can still interact with one another and share to each other their experiences in a meaningful learning environment with the aid of an expert instructor (Karal et al., 2011).

In view of this, the learners are the primary subjects of this sudden shift in the learning modality. Wherein, the learners have to adapt with the implemented changes in the teaching modality, from the traditional face-to-face to the transition in an online learning platform since the principal goal of implementing synchronous learning is for the benefit of the students and with the aim of providing them a safe and secured learning experience despite the ongoing crisis (Moorhouse, 2020). The reason for this transition is to eliminate a learning gap, especially to let the prospective language teachers continue honing their skills and be holistically developed as they progress. This is supported by the claim of Taplin et al. (2013) wherein, online resources are believed to be valuable in managing and improving class instructions and at the same time help learners be flexible in learning while developing the necessary skills they needed to attain. Hence, The utilization of the synchronous model in the teaching and learning process has been considered an opportunity for the learners to widen their perspective in terms of utilizing virtual learning platforms as a medium to learn and use the knowledge gained to improve individual skills. Thus, the establishment of synchronous learning was initiated in several institutions from around the globe during the pandemic.

However, the concern of practicing synchronous learning during the pandemic has been found to only cover a limited range of investigations. Moreover, less attention has been paid to how prospective language teachers perceive online learning and the challenges they have encountered during the course of online learning. Additionally, several research studies tend to only focus on how both the synchronous and asynchronous model can affect the students' performance and their preferences in an online class (Marom et al., 2005; Perveen, 2016; Carroll, 2011). Consequently, these investigations failed to provide essential data regarding the context the world is currently experiencing. Furthermore, irrespective of the views of Filipino prospective language teachers. As a result, only a few comprehensive observations have been conducted as to how these particular learners deal with the current situation concerning the employment of synchronous learning in their academic experience during the pandemic.

Although, in the study of Jan (2020) it can be considered relative to the present investigation since the main discussion of the paper is centered on the utilization of synchronous teaching and learning during the pandemic. However, the researcher mainly focused on exploring the issues faced by parents and the learners at the primary level concerning synchronous teaching. Nevertheless, it failed to cover the main context of the present investigation. In addition, the respondents of the study were still at the primary level while this investigation seeks to delve into a deeper understanding of the students' standpoint at the tertiary level concerning synchronous learning. Thus, the present study identifies a respondent gap since there is a necessity to provide empirical data relative to prospective language teachers' perceptions and challenges. Hence, the present investigation aims to elucidate data covering how would-be language teachers perceive their synchronous learning sessions and the challenges they have encountered while learning in the Philippine context during the pandemic. Furthermore, the researcher intends to provide a novel investigation that would be essential for future research studies having the same construct.

\section{Review of Related Literature}

\subsection{Synchronous Learning}

It is an undeniable truth that online education has already grown in popularity over the past years and is continuously receiving remarks from the public due to its accessibility, convenience, and the numerous benefits it can provide to enhance the educational system in various countries. In a similar vein, Hrastinski (2008) developed the idea that through synchronous learning, students will be more engaged and motivated to learn since there is direct monitoring of their performances during the learning process. This contention was supported by several studies (Wdowik, 2014; Taplin et al., 2013; Yang et al., 2019) in which these investigations reiterated the efficacy and effectivity of synchronous learning in enhancing the quality of instruction through the promotion of elevating the students' engagement level and establishing flexible learning.

In view of the foregoing subject, a study conducted by Rinekso and Muslim (2020) presented findings similar to that of the previous studies aforementioned wherein, they arrived at a conclusion that the students possess a positive view towards synchronous learning. In connection to this, the respondents of the said study believed that the discussion done in a synchronous session is an effective online teaching modality where questions and opinions are addressed in an instant and task negotiation, as well as planning, can proceed smoothly. 
However, due to the outbreak of COVID-19, it is a general idea that many countries were forced to take a shift from traditional face-to-face classes to virtual ones. In light of this, being accustomed to the traditional way of learning and the unfamiliarity with online education, both the teachers and the learners in the Philippines find it a new kind of learning experience, and students were somehow overwhelmed when synchronous learning was officially implemented in the country. Henceforth, the researcher would further explore the synchronous learning experience of learners residing in the Philippines, which is one among the many countries that shifted from the traditional kind of learning inside a four-walled classroom to a virtual learning platform.

\subsection{Perception towards Synchronous Learning}

The sudden shift in the learning modality has been acknowledged to receive different views and opinions from the public, especially from learners. This transition in the educational system during the pandemic is new for many, which paved a way for researchers to attempt in making investigations as the interest in this subject continuously increases in the field of research. As observed by Mohd Salman and Aziah (2012), students differ in terms of their learning styles which is an obvious result as to why they have different perspectives towards synchronous learning, which only proves why some students would prefer synchronous learning. However, it is also an undeniable fact that not all students would wholeheartedly be in favor to learn in this kind of learning modality. A large body of data concerning this subject has been increasingly adding to the list of studies in the field of research. For instance, in the study of Shukri et al. (2020), the paper has been set to investigate the perception of 250 students taking English courses through conducting a survey. The findings revealed that the students perceive this type of learning as beneficial, however, it was also noted that the respondents believe that when learning synchronously, it is not as effective as in the traditional classroom setup. Nonetheless, that is how the students perceive synchronous learning and the study only proves how valuable the views of these respondents are in terms of knowing the effectiveness of synchronous learning especially in the context of an ongoing pandemic. On top of that, Phillips (2015) theorized that online education will be more accepted by learners if they perceive that it possesses a great advantage over traditional learning, is easy to utilize, and will be compatible with their norms. Apart from that, it was also suggested that for meaningful online learning to occur, there must be feedbacks during class sessions for it to become an interactive one.

Although perception towards synchronous learning has been gradually increasing in a number of publications, the matter about prospective language teachers' perceptions towards synchronous learning during the pandemic remains largely under-researched, specifically in the focal point of Filipino learners taking language courses in the tertiary level. Therefore, this current investigation would help in providing essential data in the field of research regarding how these particular respondents in their country perceive synchronous learning.

\subsection{Challenges in Synchronous Learning}

Adjusting to the changes implemented in the educational system has not been a smooth transition for some learners. Despite the benefits that the previous studies revealed, it is notable that learners may also experience challenges in this new learning modality (Shukri et al., 2020). Consequently, researchers ought to pay great interest in examining the challenges of the learners to provide sufficient observations and be able to draw comprehensive theories regarding this matter.

In light of this, Rinekso and Muslim (2020) affirmed that the employment of synchronous learning in higher education during the pandemic imposed several challenges to the students. One of which is the challenge concerning poor internet connectivity and the other one is the misunderstanding in the tasks given to the students. Furthermore, there was also a problem with the delay of direct feedback from the teacher. Seemingly, this finding does not precisely coincide with the contention of Phillips (2015) whereas the researcher claimed that for a synchronous learning to be meaningful and interactive, there must be feedbacks directly coming from the instructor. This only shows that there is still a lot more to clarify in this subject regarding the students' challenges. Hence, the challenges encountered by the students should only be taken into account for extensive exploration, in order to establish comparative examination in between studies.

Therefore, this present investigation aims to provide comprehensive data regarding the challenges experienced by the learners imposed by the utilization of the said learning modality. Moreover, to present a clear description of the learning experiences of the students during the pandemic.

\subsection{Research Questions}

The study aims to answer the following research questions:

1. How do would-be language teachers perceive synchronous learning sessions?

2. What are the challenges in synchronous language learning? 


\section{Methodology}

\subsection{Research Design}

The present investigation employed a descriptive qualitative research design. Wherein, according to Nassaji (2015) it involves the rich collection of data coming from different sources to delve into a deeper understanding of the respective views, opinions, beliefs, and attitudes of certain individuals. In addition, the qualitative method has been widely acknowledged to play a pivotal role since it can provide a deeper exploration of human experiences (Grinnell \& Unrau, 2011; Padgett, 2008). Hence, the study utilized this approach to have a better understanding of the different perspectives of would-be language teachers towards synchronous learning. Also, to know the challenges they have encountered while utilizing the said learning modality. Moreover, the researcher facilitated a one-on-one interview with the participants, which allows the researcher to ask open-ended questions to obtain an indepth description of the experiences of the respondents (Creswell, 2003). Essentially, the employment of this research design will aid the researcher to explore the perspectives and challenges of the participants with respect to their synchronous learning experience. Wherein, the participants' experiences will provide descriptive data essential to the present investigation to attain the main objectives of this study.

\subsection{Participants of the study}

The researcher utilized a purposive sampling technique in the conduct of the study wherein, Kelly (2010) described it as the effective selection and identification of limited research resources. In addition, a total of seven students were enlisted as the participants of the study who were bonafide students from the College of Teacher Education (CTE) of Western Mindanao State University. In line with this, there were two (2) male respondents who participated in the study while the remaining five were all female respondents, wherein the participants' ages were ranging from 21-22. Furthermore, two (2) of the respondents were would-be Filipino language teachers while five (5) of the respondents were prospective English language teachers.

Essentially, the researcher adhered to certain criteria in selecting the participants who will willingly provide the necessary data needed in the investigation. In connection to this, the following are the criteria set in selecting the participants, (1) the participant must be a student taking up a bachelor's degree either in English or Filipino, (2) the participant must be enrolled in the second semester of the school year 2020-2021, and (3) the participant must be part of the present online-based education system.

\subsection{Research Instrument}

To determine how would be-language teachers perceive synchronous learning and the challenges they have encountered during the course of instruction, a semi-structured interview was administered by the researcher. In line with this, McIntosh and Morse (2015) posited the idea that semi-structured interviews are used to ascertain the responses of the participants regarding their experiences on a particular topic or phenomenon. Moreover, open-ended interview questions were prepared by the researcher to be administered to the participants of the study, to obtain the learning experiences of the respondents during the pandemic. Through the utilization of the two main research questions, a total of six interview questions were established. The interview questions consist of two parts. On the one hand, the first part aimed to obtain data concerning the students' perspective towards synchronous learning wherein, two primary interview questions were set. On the other hand, the second part was allotted with four items, intended to gather information concerning the challenges that the participants have encountered during synchronous learning.

\subsection{Data Gathering Procedure}

The participants of the study received a consent letter from the researcher wherein, the letter contains essential information about the conduct of the present investigation, statements about the confidentiality of the interview, and their consent for participating in the study as one of the respondents. Subsequently, for the participants who agreed to proceed with the interview, a semistructured interview was administered, and probing questions were asked during the interview proper aside from the prepared interview questions, all accomplished through a phone call. The interviews lasted for about 12-20 minutes for every participant. The gathered responses were then transferred to Microsoft Word, a primary tool for data coding for the analysis and interpretation of the results (Watkins, 2017). Thereafter, the developed themes which were based on the perceptions and challenges of wouldbe language teachers were used in the process of analyzing the collected data.

\subsection{Method of Analysis}

In analyzing the collected data in this study, the researcher utilized the thematic analysis which Vaismoradi et al. (2013) posited as the process of finding repeated meanings across a data set. Relatively, a theme refers to the specific pattern found in the data set which is primarily aligned to the research questions of the study (Braun \& Clarke, 2006). Furthermore, the construct of themes from the gathered responses will be utilized in order to substantiate the analysis of the data. 


\section{Results and Discussion}

Using the data gathered during the interview, the researcher was able to classify the themes that appeared from the following categories: (1) perceptions towards synchronous learning and (2) the challenges encountered during synchronous learning. The developed themes along with the two categories will be utilized in the analysis of would-be language teachers' perceptions and challenges towards synchronous language learning. Moreover, table 1 shows the different perceptions of the participants regarding synchronous learning while table 2 presents the challenges encountered by the participants.

Table 1: Perceptions towards Synchronous Learning Sessions

\begin{tabular}{|c|c|c|}
\hline Themes & Excerpts & Percentage \\
\hline $\begin{array}{l}1 . \quad \text { Learners perceive } \\
\text { synchronous learning as a } \\
\text { challenging learning experience. }\end{array}$ & $\begin{array}{l}\text {... find synchronous classes challenging, considering that } \\
\text { there are a lot of barriers in this kind of learning modality. } \\
\text { For instance, the poor internet connectivity which is indeed } \\
\text { inevitable, because whether you are using Wi-Fi or mobile } \\
\text { data, one can still experience problems in internet } \\
\text { connectivity... (Respondent 3) } \\
\text {...challenging because this type oflearning is new to me and } \\
\text { I am not used to it, so there are teaching tools and platforms } \\
\text { that I am not familiar with. Also, in synchronous learning } \\
\text { there will always be circumstances that we can't control } \\
\text { such as technical problems and there was a time wherein, I } \\
\text { was supposed to report in class but due to an unstable } \\
\text { internet connection, I wasn't able to present my topic and } \\
\text { attend my class. (Participant } 4 \text { ) } \\
\text { Physically it can be challenging because it is a shift on our } \\
\text { end, the students as well as we are not used to having our } \\
\text { class online, we're not really into using applications for our } \\
\text { class... It is challenging because we must also consider the } \\
\text { internet connection of our students as well as the teacher. } \\
\text { And also, we must also consider the storage that these } \\
\text { applications can compromise in our respective gadgets. } \\
\text { (Respondent } 7 \text { ) }\end{array}$ & $\begin{array}{l}5 \text { out of } 7 \text { or } \\
71.43 \% \text { of the } \\
\text { respondents }\end{array}$ \\
\hline $\begin{array}{l}\text { 2. Synchronous learning is } \\
\text { considered stressful and } \\
\text { exhausting among students. }\end{array}$ & $\begin{array}{l}\text {...it is exhausting because the whole week you have } \\
\text { classes... it gets really exhausting because I cannot stay long } \\
\text { staring at the screen because I get a headache... } \\
\text { (Respondent 5) } \\
\text {..I think online classes are also quite stressful since the } \\
\text { course that I took is really demanding, there are really lots } \\
\text { of activities given... which makes it difficult for me to } \\
\text { manage my time anymore like I also have other } \\
\text { responsibilities at home so it's really difficult for me to } \\
\text { manage my time because of the school works... I think that } \\
\text { is how loads of works affect my studies during an online } \\
\text { class. (Respondent 6) }\end{array}$ & $\begin{array}{l}4 \text { out of } 7 \text { or } \\
57.14 \% \text { of the } \\
\text { respondents }\end{array}$ \\
\hline
\end{tabular}




\begin{tabular}{|c|c|c|}
\hline $\begin{array}{l}\text { 3. Synchronous learning is } \\
\text { beneficial to learners during the } \\
\text { pandemic. }\end{array}$ & $\begin{array}{l}\text {...During online classes I also visited some educational sites } \\
\text { in which they can really help us to gain knowledge about } \\
\text { the task that they are giving about the topic being } \\
\text { discussed... (Respondent 1) }\end{array}$ & $\begin{array}{l}3 \text { out of } 7 \text { or } \\
42.86 \% \text { of the } \\
\text { respondents }\end{array}$ \\
\hline $\begin{array}{l}\text { 4. Learning synchronously is fun } \\
\text { and interesting as perceived by } \\
\text { the learners. }\end{array}$ & 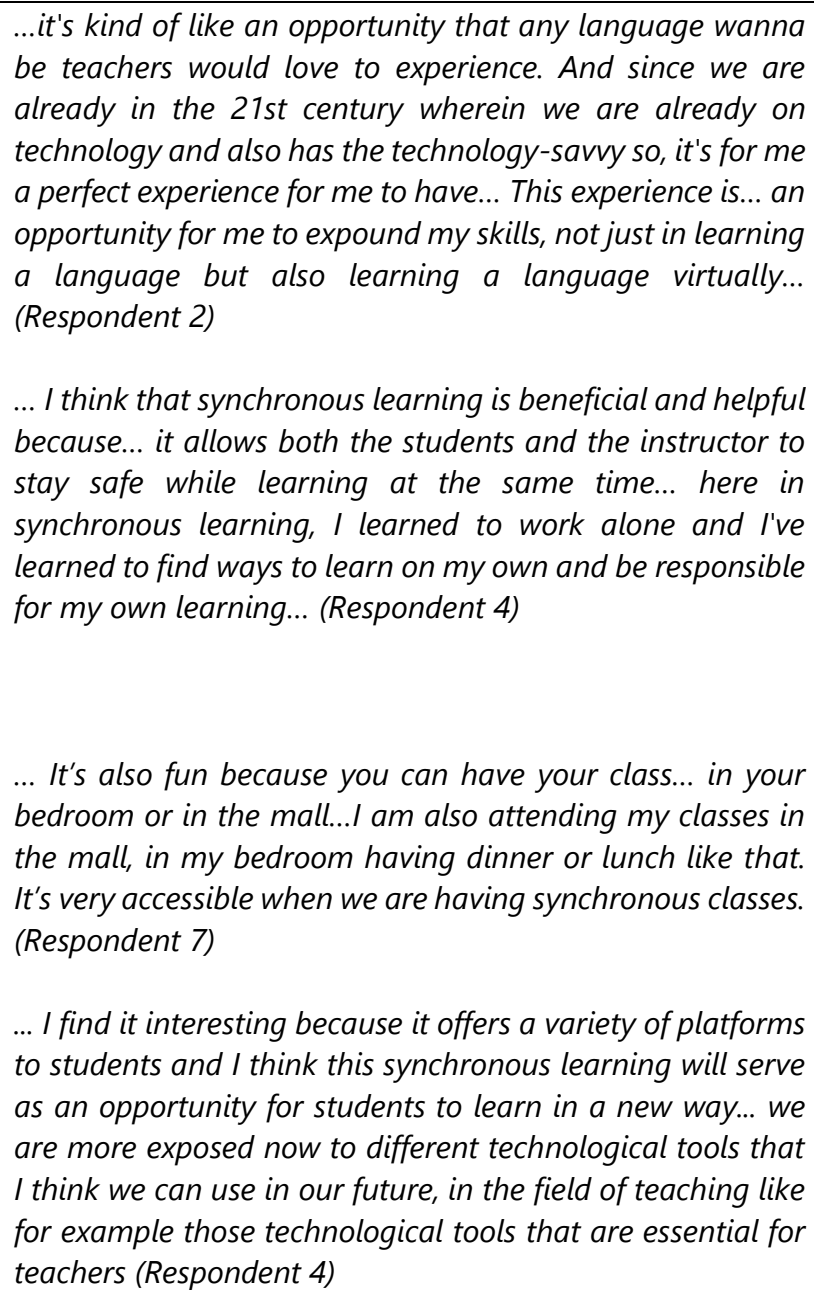 & $\begin{array}{l}2 \text { out of } 7 \text { or } \\
28.57 \% \text { of the } \\
\text { respondents }\end{array}$ \\
\hline
\end{tabular}

Table 1 presents the different perceptions of the participants concerning synchronous learning sessions. Additionally, it can be noted that a total of five themes were established in this category which means that the respondents view synchronous learning sessions in five different ways.

On top of the list is that the learners perceive synchronous learning as a challenging learning experience. Out of the total of seven respondents, five of them, or $71.43 \%$ have equally perceived it as challenging. Evidently, the excerpt,

"I find synchronous classes challenging, considering that there are a lot of barriers in this kind of learning modality. For instance, the poor internet connectivity" (Participant 3)

only shows how synchronous learning can be challenging for the students. Moreover, the respondents explained that the main reason why synchronous learning session was perceived as challenging was due to issues concerning poor internet connectivity which can affect their learning hence, this problem imposes a challenge to the students in attending a problem-free class session. In the same vein, Park and Bonk (2007) provided the same contention since it was observed that network connection problems forced the learners to get disconnected in class which is a major drawback in synchronous learning. Subsequently, the internet connectivity issue is one of the common and significant problems in synchronous learning faced by many students (Karal et al., 2011). 
Additionally, the respondents also considered it a stressful and exhausting learning experience. Four of the respondents shared the same view about it whereas, participants 3 and 5 both expressed that the cause of their stress was their class schedule wherein, they have to attend classes for a long period of time during the day without enough time to rest. Additionally, the participants were being bombarded with activities that they tend to have a hard time balancing their time.

"There are really lots of activities given... which makes it difficult for me to manage my time" (Participant 6)

Consequently, the heavy workload has been the major concern of one of the respondents resulting in a stressful situation wherein, managing personal space and time has become difficult due to activities to be submitted by the students. With reference to this, Jan (2020) claimed that the activities given during synchronous learning sessions vary however, it can be noted that there was an increase in the number of activities provided to the learners. This implies that the students were challenged in complying with the activities in online education.

Despite the previous themes which visibly seem to be a negative remark on synchronous learning, the participants have also considered its benefits. Respondents 1 and 2 both perceived it beneficial as it serves as an opportunity for the students to widen their knowledge about the benefits of technology in education. While respondent 4 claimed that synchronous learning sessions resulted in honing the students into becoming independent learners. Seemingly, during the course of instruction, the learners depend solely on themselves, monitoring their progress and accomplishing all the tasks without the assistance of a classmate or the teacher, hence, their sense of independence increased during synchronous learning. In addition, respondent 1 opined that it provides wider access to educational sites which can aid learners in their studies. This was supported by the claim of Mohd Salman and Aziah (2012) which pointed out that synchronous learning offers wider access to information and tends to enhance the learning experience of the learners.

Lastly, apart from the benefits that synchronous learning can provide, the respondents also considered it as a fun and interesting learning experience. In view of this, Respondent 7 claimed that it was fun and engaging in a way that synchronous learning was very accessible any time of the day as shown in the excerpt below,

\section{"It's also fun because you can have your class... in your bedroom or in mall... It's very accessible when we are having synchronous classes." (Participant 7)}

This contention can be subjected to similar findings in the study of Khan et al. (2021) and Shukri et al. (2020) wherein the respondents tend to be engaged in this learning modality due to the flexibility and comfort it can give to the students while learning at home.

Table 2: Challenges in Synchronous Language Learning

\begin{tabular}{|c|c|c|}
\hline Themes & Excerpts & Percentage \\
\hline $\begin{array}{l}\text { 1. Internet connectivity issues } \\
\text { forced learners to undergo a } \\
\text { challenging } \\
\text { experience. }\end{array}$ & $\begin{array}{l}\text {...my internet connection is very slow, therefore, I really } \\
\text { cannot join the class... I have experienced low internet } \\
\text { connection that's why I keep disconnecting in the class... } \\
\text { (Respondent 6) } \\
\text {...weak signal is actually a factor for me to not learn very } \\
\text { well because sometimes when the teacher discusses I can't } \\
\text { understand well, I cannot comprehend well because the } \\
\text { voice is really choppy, so it frustrates me because I cannot } \\
\text { understand... I was about to do a presentation in the class... } \\
\text { the internet do not cooperate and it resulted to... my } \\
\text { presentation did not go well due to that problem. } \\
\text { (Respondent 2) } \\
\text {... was supposed to report in class but due to an unstable } \\
\text { internet connection I wasn't able to present my topic and } \\
\text { attend my class... (Respondent 4) }\end{array}$ & $\begin{array}{l}7 \text { out of } 7 \text { or } 100 \% \\
\text { of the respondents }\end{array}$ \\
\hline
\end{tabular}


2. The limited interaction between the students and the teacher constituted learning motivation among the learners.

3. Experiencing technical difficulties challenged the students during synchronous learning.

4. Noises coming from the learners' environment imposed barriers to learning.

5. The lack of gadgets inflicted difficulties on learners during synchronous learning. ...synchronous learning limits the interaction between the teachers and the student...I feel unmotivated during synchronous learning because it limits my interaction with my co-students and the teacher and also... (Respondent 3)

...there are only limited interactions like for the whole time, the teacher is only discussing... she only discuss and discuss... as for me it is really boring and it doesn't encourage me to pay attention. (Respondent 6)

...technical difficulties during reporting and presentation are really a hindrance for me to attend the online class. ... when it is our time to report already, technical glitches came in at my end... it really gave me a hard time to join and participate in the class discussion. (Respondent 6)

...challenge is that when you are having technical difficulties say for example the bugs, the glitches in your device, it will really affect your classes online... the students not having to understand what the teacher is saying as well as what the presentation is all about. (Respondent 7)

... When I attend online classes every day, my cousins or my niece and nephews run around and I get really distracted, the people around me like my siblings... I get really distracted like I lose my focus... when I hear the noises I get really out of focus... (Respondent 5)

... being distracted in an online class is indeed a challenge because we cannot actually focus on what the teacher is explaining during the virtual session and we cannot really listen carefully to what the teacher is saying and that indeed affects your learning of the lesson... I cannot actually focus on what is being explained or what is being taught in the virtual class. (Respondent 3)

...background noises, because we cannot control especially the sound of the animals, the chickens and all and it really interrupts me especially when you're reciting, talking to the class because it's very uncomfortable... (Respondent 1)

...limited resources also because I only have my mobile phone... it's difficult because I have many classes in a day and I have to charge my phone while I'm getting on class... I'm going to do my requirements, in my PowerPoint presentation, encoding and all so, it's really difficult to edit just using my phone... (Respondent 4)
3 out of 7 or $42.86 \%$ of the respondents

2 out 7 or $28.57 \%$ of the respondents
4 out of 7 or $57.14 \%$ of the respondents

1 out of 7 or $14.28 \%$ of the respondents 
Table 2 reveals the different challenges the students have encountered during synchronous learning. Furthermore, it can be inferred that a total of seven themes were established in this category.

First, the students explicated that they are prone to experience poor internet connectivity issues. The data displayed in the first theme appears that all seven participants can relate to this problem. It only means that these students have all experienced getting interrupted by poor internet during synchronous class sessions.

"I cannot comprehend well because the voice is really choppy, so it frustrates me because I cannot understand..." (Participant 2)

respondent 2 reiterated that whenever the internet gets slow, the voices in the learning platform become inaudible hence, experiencing this problem poses a challenge to the learners in understanding the one speaking during class sessions, and the chances of comprehension on the lesson being discussed decreases.

In view of this, the claim of the respondents was validated in the study of Mahyoob (2020) wherein the investigation led to a conclusion that one of the main challenges experienced by learners during the pandemic is the issue of the speed of the internet. The researcher further stated that learners missed classes due to poor internet connection which is relative to the explanation of respondent 6 as presented in this excerpt,

"...my internet connection is very slow, therefore, I really cannot join the class" (Participant 6)

This simply means that learners from several countries have also been experiencing the same challenge about their e-learning experience.

In addition to the list of challenges that the respondents have encountered is the limited interaction between the students and the teacher. Three among the seven respondents or $42.86 \%$ believed it to be a challenge as shown in one of the excerpts below,

\section{"...I feel unmotivated during synchronous learning because it limits my interaction with my co-students and the} teacher also..." (Participant 3)

It can be inferred that there is less interaction during synchronous learning sessions and the tendency to feel unmotivated during class may happen to the students as what the respondent is trying to relate. In a corroborating statement, Belgica et al. (2020) explained that due to the lack of interaction, students may also experience a lack of interest which may affect their academic performance. Moreover, it has been noticed that during class, most of the discussion is only coming from the teacher and there is less involvement of learners' participation which can compromise the ideals of a meaningful learning experience. Seemingly, according to Karal et al. (2011) for a meaningful learning experience to occur, there must be a balanced involvement between the students and the teacher wherein, the students can also share and relate their ideas to the class.

Apparently, technical difficulties have also challenged the students wherein, glitches, lags, and bugs have been a common concern among the students.

"when it is our time to report already, technical glitches came in at my end... it really gave me a hard time to join and participate in the class discussion." (Participant 6)

The difficulty during class presentations, understanding the discussion and attending the class place the students in a challenging situation due to this matter as one of the respondents discussed. This contention was supported by Rinekso and Muslim (2020) wherein technical issues are seen to be one of the most frequently observed problems in technological-based learning.

The participants have also explained that there are several distractions in the surroundings which imposed difficulty in concentrating on the discussion. Furthermore, respondent 5 opined that there is a tendency to lose one's focus during class discussions due to unnecessary noises as provided in this excerpt,

"I get really distracted like I lose my focus... when I hear the noises I get really out of focus..." (Participant 5)

This implies that distractions like noises coming from the animals and in the neighborhood as well as the people in the surroundings are some of the factors that distract the students during their class. Supporting this statement is the contention of Belgica et al. (2020) wherein the students face challenges when it comes to concentrating in class. Since the majority of the students are having classes at home, the environment has become a factor for the students to experience concentration problems while learning. Evidently, this has been one of the challenges that the respondents have pointed out in this investigation.

The last challenge as shown in the excerpt below pertains to the lack of gadgets to be used during synchronous learning. 
"I'm going to do my requirements, my PowerPoint presentation, encoding and all so, it's really difficult to edit just using my phone..." (Participant 4)

The participant made a remark that having a phone alone is challenging since that gadget will be utilized for many purposes already. For instance, it is difficult on the part of the students to edit large files using only a phone due to its limited storage capacity as well as open other sites when the teacher instructed during a class discussion all at once. Thus, the lack of gadgets imposed a challenge to the students while learning during the pandemic. This standpoint bears the same remark with Mahyoob (2020) wherein the researcher postulated that there are learners who suffer from the lack of high-quality learning devices which may affect the learning outcomes of the students.

Moreover, Joaquin et al. (2020) stipulated that due to the pandemic, the public was forced to rely on technology for the delivery of instruction hence, this only suggests the importance of gadgets used by the learners in their synchronous learning. However, Baticulon et al. (2021) theorized that providing learners the necessary gadgets needed in online learning will not guarantee a successful learning outcome, especially when the major challenges experienced by learners were not adequately addressed.

\section{Conclusion}

This study aimed to explore how would-be language teachers perceive synchronous learning and the challenges the learners have encountered when learning in this kind of modality. Moreover, the findings of this investigation reveal that the respondents have varied perspectives regarding synchronous learning.

Essentially, it can be inferred that some students perceive it as beneficial since it can provide the learners an opportunity to explore various learning platforms and educational sites that can aid the students while learning during the pandemic. In addition, learners have also considered it as a fun and engaging learning experience due to its accessibility and the comfort it can provide to the students as supported by Khan et al. (2021) and Shukri et al. (2020). However, remarks such as it is challenging, stressful, and exhausting were also pointed out in this study as perceived by the students.

Furthermore, with regards to the challenges experienced by the learners, it can be concluded that internet connectivity issues, limited interaction between the students and the teacher, the technical difficulties during class presentations and attending the class, the distractions from the learning environment, and the lack of gadget were the frequently observed challenges encountered by the students during the course of learning.

Seemingly, synchronous learning was implemented to shed light on the educational paradigm of the Philippines during the pandemic. This kind of learning modality was enforced to ensure that a learning gap will not befall as well as to continue the endeavor of securing a meaningful learning experience amidst the outbreak of COVID-19 that has affected the conventional delivery of instruction. Hence, if the teaching and learning process will be executed in the most effective manner while addressing the needs and concerns of the students, then this endeavor will be fulfilled and as a result, a successful education amidst the crisis will be observed.

\section{References}

[1] Baticulon, R., Sy, J., Alberto, N., Baron, M., Mabulay, R., Rizada, L., Tiu, C., Clarion, C., \& Reyes, C. (2021). Barriers to online learning in the time of covid-19: A national survey of medical students in the Philippines. Medical Science Educator, 31, 615-626.

[2] Belgica, C., Calugan J., Dumo, J., \& Simber, L. (2020). Online distance learning: Thematic study on the challenges faced by Educare College Inc. primary pupils. Advanced Research in Education, Teaching and Learning, 1-18.

[3] Berge, Z. (1995). The role of the online instructor/facilitator. Educational Technology, 35(1), 22-30.

[4] Braun, V., \& Clarke, V. (2006). Using thematic analysis in psychology. Qualitative Research in Psychology, 3(2), 77-101.

[5] Carroll, N. (2011). Evaluating online asynchronous support in the institutes of technology Ireland. AISHE-J, 3(2), 1-23.

[6] Creswell, J. W. (2003). Research design: Quantitative, qualitative, and mixed methods approach. Thousand Oaks, CA: Sage.

[7] Driscoll, M. (2002). Web-based training: Creating e-learning experiences. San Francisco: Jossey-Bass/Pfeiffer.

[8] Gough, M. (2006). Video conferencing over IP configure, secure, and troubleshoot. Syngress Publishing, Inc.

[9] Grinnell, R. M., \& Unrau, Y. A. (2011). Social work research and evaluation: Foundations of evidence-based practice (9th ed.). Oxford, England: Oxford University Press.

[10] Horton, W. K. (2000). Designing web-based training: How to teach anyone anything anywhere anytime. New York: John WileyandSons.

[11] Hrastinski, S. (2008). Asynchronous and synchronous e-learning. Educause quarterly, 31, 51-55.

[12] Jan, A. (2020). A phenomenological study of synchronous teaching during covid-19: A case of an international school in Malaysia. Social Sciences \& Humanities, 2, 1-10.

[13] Joaquin, J., Biana, H., \& Dacela, M. A. (2020). The Philippine higher education sector in the time of covid-19. Frontiers in Education, 5, 1-6.

[14] Karal, H., Cebi, A., \& Turgut, Y. (2011). Perceptions of students who take synchronous courses through video conferencing about distance education. TOJET: The Turkish Online Journal of Educational Technology, 10(4), 276-293.

[15] Kelly, S. (2010). Qualitative interviewing techniques and styles. The Sage Handbook of Qualitative Methods in Health Research. 
[16] Khalil, R., Mansour, A., Fadda, W., Almisnid, K., Aldamegh, M., Al-Nafeesah, A., Alkhalifa, A., \& Al-Wutayd, O. (2020). The sudden transition to synchronized online learning during the Covid-19 pandemic in Saudi Arabia: a qualitative study exploring medical students' perspectives. BMC Medical Education, 20, 2-10.

[17] Khan, M. A., Vivek., Nabi, M. K., Khojah, M., \& Tahir, M. (2021). Students' perception towards e-learning during the covid-19 pandemic in India: An empirical study. Sustainability, 13, 1-14.

[18] Mahyoob, M. (2020). Challenges of e-learning during the covid-19 pandemic experienced by EFL learners. Arab World English Journal, 11(4), 351-362.

[19] Malik, M., Fatima, G., Hussain, A., \& Sarwar, A. (2017). E-learning: Students' perspectives about asynchronous and synchronous resources at the higher education level. Bulletin of Education and Research, 39(2), 183-195.

[20] Marom, R., Saporta, K., \& Caspi, A. (2005). Synchronous vs. asynchronous tutorials: Factors affecting students' preferences and choices. Journal of Research on Technology in Education, 37(3), 245-262.

[21] McIntosh, M., \& Morse, J. (2015). Situating and constructing diversity in semi-structured interviews. Global Qualitative Nursing Research, 112.

[22] Mcloughlin, C., \& Lee, M. (2010). Personalized and self-regulated learning in the web 2.0 era: International Exemplars of innovative pedagogy using social software. Australasian Journal of Educational Technology, 26, 32-45.

[23] Mohd Salman, A. M., \& Aziah, I. (2012). Learning styles and perception of engineering students towards online learning. Procedia-Social and Behavioral Sciences, 69, 669-674.

[24] Moorhouse, B. (2020). Adaptations to a face-to-face initial teacher education course 'forced' online due to the covid-19 pandemic. Journal of Education for Teaching, 1-3.

[25] Nassaji, H. (2015). Qualitative and descriptive research: Data type versus data analysis. Language Teaching Research, 19(2), $129-132$.

[26] Padgett, D. (2008). Qualitative methods in social work research (2nd ed.). Los Angeles, CA: Sage.

[27] Park, Y. J., \& Bonk, C. (2007). Synchronous learning experiences: Distance and residential learners' perspectives in a blended graduate course. Journal of Interactive Online Learning, 6(3), 245-264.

[28] Perveen, A. (2016). Synchronous and asynchronous e-language learning: A case study of the virtual university of Pakistan. Open Praxis, 8(1), 21-39.

[29] Phillips, J. A. (2015). Replacing traditional live lectures with online learning modules: Effects on learning and student perceptions. Currents in Pharmacy Teaching and Learning, 7(6), 738-744.

[30] Rinekso, A. B., \& Muslim, A. B. (2020). Synchronous online discussion: Teaching English in higher education amidst the covid-19 pandemic. JEES Journal of English Educators Society, 5(2), 155-162.

[31] Rosenberg, M. J. (2001). E-learning: Strategies for delivering knowledge in the digital age. New York: McGraw-Hill.

[32] Shahabadi, M., \& Uplane, M. (2015). Synchronous and asynchronous e-learning styles and academic performance of e-learners. ProcediaSocial and Behavioral Sciences, 176, 129-138.

[33] Shukri, A., Nordin, L., Salleh, F., Raidzwan, S., \& Ahmad, R. (2020). UniKL students' perception of synchronous learning using ICT as learning tools to learn English. Journal of critical reviews, 793-796.

[34] Taplin, R. H., Kerr, R., \& Brown, A. M. (2013). Who pays for blended learning? A cost-benefit analysis. The Internet and Higher Education, 18(1), 61-68.

[35] Vaismoradi, M., Turunen, H., \& Bondas, T. (2013). Content analysis and thematic analysis: Implications for conducting a qualitative descriptive study. Nursing and Health Sciences, 15(3), 398-405.

[36] Watkins, D. (2017). Rapid and rigorous qualitative data analysis: The "RADaR" technique for applied research. International Journal of Qualitative Research, 16(1), 1-9.

[37] Wdowik, S. (2014). Using asynchronous online learning environment to promote and enhance transactional engagement beyond the classroom. Campus-Wide Information Systems.

[38] Yang, J., Yu, H., \& Chen, N. (2019). Using a blended synchronous classroom approach to promote learning performance in a rural area. Computers and Education, 141(1), 103-619 